\title{
Enhanced Grain Refinement and Precipitation of the IEECAPed Mg-Sm-Zn-Zr Alloy by Nd Addition
}

\author{
Kun Liu ${ }^{1}$, Sicong Zhao ${ }^{1, *}$, Changliang Wang ${ }^{1}$, Liping Wang ${ }^{1}$, Yicheng Feng ${ }^{1}$, Dongrong Liu ${ }^{1}$, Jingfang $\mathrm{Li}^{2, *}(\mathbb{D}$ \\ and Zhiwei Wang ${ }^{3}$ \\ 1 Key Laboratory of Advanced Manufacturing and Intelligent Technology (MOE), School of Material Science \\ and Chemical Engineering, Harbin University of Science and Technology, Harbin 150080, China; \\ 1khust@126.com (K.L.); hlgwangcl@163.com (C.W.); lp_wang2003@126.com (L.W.); fyc7806067@163.com (Y.F.); \\ hitldr@126.com (D.L.) \\ 2 Key Laboratory of Functional Inorganic Material Chemistry (MOE), School of Chemistry and Materials \\ Science, Heilongiiang University, Harbin 150080, China \\ 3 Aero Engine Corporation of China, Harbin Dongan Engine Co., Ltd., Harbin 150060, China; xztvcn@163.com \\ * Correspondence: zscwr@163.com (S.Z.); fjlaaa.ok@163.com (J.L.)
}

check for updates

Citation: Liu, K.; Zhao, S.; Wang, C.; Wang, L.; Feng, Y.; Liu, D.; Li, J.;

Wang, Z. Enhanced Grain Refinement and Precipitation of the IEECAPed $\mathrm{Mg}-\mathrm{Sm}-\mathrm{Zn}-\mathrm{Zr}$ Alloy by Nd Addition. Materials 2021, 14, 5667. https:// doi.org/10.3390/ma14195667

Academic Editor: Pavel Novak

Received: 13 September 2021

Accepted: 26 September 2021

Published: 29 September 2021

Publisher's Note: MDPI stays neutral with regard to jurisdictional claims in published maps and institutional affiliations.

Copyright: (c) 2021 by the authors. Licensee MDPI, Basel, Switzerland. This article is an open access article distributed under the terms and conditions of the Creative Commons Attribution (CC BY) license (https:/ / creativecommons.org/licenses/by/ $4.0 /)$.

\begin{abstract}
Achieving magnesium-rare earth alloys with excellent mechanical properties remains a challenging goal in the aerospace industry. The integrated extrusion and equal channel angular pressing were employed to refine grain and improve the mechanical properties of $\mathrm{Mg}-\mathrm{xNd}-2.0 \mathrm{Sm}$ $0.4 \mathrm{Zn}-0.4 \mathrm{Zr}$ alloys. The effect of $\mathrm{Nd}$ element on microstructure and mechanical properties of the extruded and subsequently aged alloys were carried out by varying the amount of the Nd element from $0 \mathrm{wt} . \%$ to $2.5 \mathrm{wt}$.\%. The optical microscopy results indicated that the grain size was remarkably refined by the addition of $\mathrm{Nd}$ element. The grain size decreased from $29.7 \mu \mathrm{m}$ to $10.9 \mu \mathrm{m}$ with increasing of the $\mathrm{Nd}$ element from $0 \mathrm{wt} . \%$ to $2.5 \mathrm{wt}$.\%. The transmission electron microscopy results showed that the nano-scaled basal lamellar precipitates, prismatic lamellar precipitates and granular precipitates were formed in $\alpha-\mathrm{Mg}$ matrix. The amount of the precipitates increased significantly by the addition of Nd. Moreover, the strength of the alloys significantly improved with Nd. Superior strength and considerable plasticity were obtained as the content of $\mathrm{Nd}$ element reached $2.0 \mathrm{wt} . \%$, while the tensile strength of the Mg-2.0Nd-Sm-Zn-Zr alloy ( $315 \pm 5 \mathrm{MPa}$ ) increased by $35.8 \%$ with respect to the $\mathrm{Nd}$-free alloy $(232 \pm 3 \mathrm{MPa})$.
\end{abstract}

Keywords: Mg-rare earth alloy; IEECAP; microstructure; mechanical properties

\section{Introduction}

Magnesium (Mg) alloys, as the lightest and eco-friendly metal structural material, have received wide attention [1-4]. Nevertheless, the poor strength of the Mg alloys limits their applications in aerospace industry [5,6]. Among the widely known strategies to improve the strength and plasticity of $\mathrm{Mg}$ alloys in industrial applications, severe plastic deformation (SPD) processing is an ideal choice. This is especially seen in equal channel angular pressing (ECAP), which induces enormous levels of strain into the alloys without changing the shape of the sections of the sample [7-10]. However, ECAP is mainly focused on Mg-Al alloys [11,12]. The mechanical properties of ECAPed Mg-Al alloys could not meet the further application of aerospace now. In this regard, more researchers have been paying attention to Mg-rare earths (RE) alloys. Extensive investigations have proved that RE could improve the mechanical properties of $\mathrm{Mg}$ alloys significantly. Nevertheless, the study for ECAPed Mg-light RE alloys is insufficient. Recently, samarium (Sm) has been widely used to improve the strength of $\mathrm{Mg}$ alloys. The cost performance and precipitation strengthening ability of Sm-containing Mg alloys are excellent [13-16]. Moreover, the neodymium (Nd) element is a high-efficiency light RE element used to enhance the mechanical properties of $\mathrm{Mg}$ alloys. The addition of $\mathrm{Nd}$ element in $\mathrm{Mg}-\mathrm{Y}-\mathrm{Zr}$ alloys could improve its strength 
due to precipitation strengthening and grain refinement, according to the studies by $\mathrm{Xu}$ et al. [17]. Wang et al. [18] showed that the $\mathrm{Nd}$ could endow the Mg-2Zn-0.46Y alloy with homogeneous and fine grain structures. Guadalupe et al. [19] applied the Nd addition to reduce the yield asymmetry of $\mathrm{Mg}$-Zn alloys. In general, the type of the precipitates consists of $\beta$ series precipitates and $\gamma$ series precipitates in $\mathrm{Mg}-\mathrm{Nd}(-\mathrm{Zn})$ alloys [20].

For these reasons, $\mathrm{Mg}-\mathrm{Nd}-\mathrm{Sm}-\mathrm{Zn}-\mathrm{Zr}$ alloys were designed and prepared according on the advantages of multi-component alloying. In the present work, in order to simplify the traditional ECAP techniques, multi-pass of ECAP process are optimized to one pass. Moreover, in order to maintain a considerable strain levels, the angle $\phi$ between the equal channels is reduced to $90^{\circ}$. The integrated extrusion and equal channel angular pressing (IEECAP) could significantly improve extrusion efficiency, and the size of extruded bar are not limited by the extrusion mold [21]. Therefore, the IEECAP was employed to refine grain and enhance the mechanical properties of the Mg-Nd-Sm-Zn-Zr alloys. Furthermore, the aging treatment is an extremely effective way to enhance the strength of the Mg-RE alloys. The $\mathrm{Nd}$ element played a key role in the microstructure and mechanical properties of the IEECAPed and subsequently aged $\mathrm{Mg}-\mathrm{Nd}-\mathrm{Sm}-\mathrm{Zn}-\mathrm{Zr}$ alloys. However, the effect of $\mathrm{Nd}$ on microstructure and mechanical properties of $\mathrm{Mg}-\mathrm{Nd}-\mathrm{Sm}-\mathrm{Zn}-\mathrm{Zr}$ alloys is studied inadequately.

Herein, the IEECAP and subsequent ageing were employed to enhance the mechanical properties of the Mg-Nd-Sm-Zn-Zr alloy. The effect of Nd element on grain refinement and precipitation of the $\mathrm{Mg}-\mathrm{Nd}-\mathrm{Sm}-\mathrm{Zn}-\mathrm{Zr}$ alloy was carried out by varying the amount of the $\mathrm{Nd}$ element from $0 \mathrm{wt} . \%$ to $2.5 \mathrm{wt} . \%$.

\section{Materials and Methods}

The compositions of Mg-xNd-2.0Sm- $0.4 \mathrm{Zn}-0.4 \mathrm{Zr}$ alloys ( $\mathrm{x}=0 \mathrm{wt} . \%, 0.5 \mathrm{wt} . \%, 1.0 \mathrm{wt} . \%$, $1.5 \mathrm{wt} . \%, 2.0 \mathrm{wt} . \%$ and $2.5 \mathrm{wt} . \%$ ) alloys were shown in Table 1 . The alloys were prepared from $\mathrm{Mg}$ ingots $(\mathrm{Mg}>99.9$ wt.\%), $\mathrm{Zn}$ ingots $(\mathrm{Zn}>99.99$ wt.\%), Mg-30 wt.\% Sm alloy, Mg-30 wt. $\% \mathrm{Zr}$ alloy and Mg-25 wt. $\% \mathrm{Nd}$ alloy. The alloys were melted at $780{ }^{\circ} \mathrm{C}$ under the protective atmosphere of $\mathrm{CO}_{2}$ and $\mathrm{SF}_{6}$. The melt was stirred for $300 \mathrm{~s}$, then standing for $180 \mathrm{~s}$. The alloys were then cast into metal mold at $720^{\circ} \mathrm{C}$. The material of the metal mold was low-carbon steel. In order to prevent gas holes and cold shut of the ingots, the metal mold was preheated at $200{ }^{\circ} \mathrm{C}$ for more than $5 \mathrm{~h}$ prior to casting. The schematic diagram of the IEECAP process and macrograph of the IEECAPed sample were shown in Figure 1. The range of the extrusion pressure of the IEECAP is $700 \mathrm{MPa}$ to $1100 \mathrm{MPa}$ and the speed of the plunger is approximately $3 \mathrm{~mm} \mathrm{~s}^{-1}$. The IEECAPed samples were aged at $190{ }^{\circ} \mathrm{C}$ for $18 \mathrm{~h}$. The mechanical properties were characterized by tensile tests. The tensile test fracture morphologies of the alloys were observed and analyzed by scanning electron microscope (SEM, Apreo C, Thermo Fisher Scientifific Inc., Hillsboro, OR, USA). The microstructure was observed and analyzed by optical microscopy (OM, OLYMPUS-GX71, Olympus Co., Tokyo, Japan) and transmission electron microscopy (TEM, JEM-2100, JEOL Co. Ltd., Tokyo, Japan). In this work, the linear intercept method was employed to quantitatively analyze the average grain size.

Table 1. Nominal compositions and actual compositions of Mg-xNd-2.0Sm-0.4Zn-0.4Zr alloys.

\begin{tabular}{cccccc}
\hline Nominal Compositions (wt.\%) & \multicolumn{4}{c}{ Actual Compositions (wt.\%) } \\
& Nd & Sm & Zn & Zr & Mg \\
\hline Mg-2.0Sm-0.4Zn-0.4Zr & - & 2.03 & 0.41 & 0.42 & Bal. \\
Mg-0.5Nd-2.0Sm-0.4Zn-0.4Zr & 0.51 & 2.05 & 0.42 & 0.41 & Bal. \\
Mg-1.0Nd-2.0Sm-0.4Zn-0.4Zr & 1.04 & 2.01 & 0.41 & 0.42 & Bal. \\
Mg-1.5Nd-2.0Sm-0.4Zn-0.4Zr & 1.54 & 2.07 & 0.40 & 0.42 & Bal. \\
Mg-2.0Nd-2.0Sm-0.4Zn-0.4Zr & 2.03 & 2.05 & 0.41 & 0.41 & Bal. \\
Mg-2.5Nd-2.0Sm-0.4Zn-0.4Zr & 2.51 & 2.04 & 0.42 & 0.41 & Bal. \\
\hline
\end{tabular}


(a)
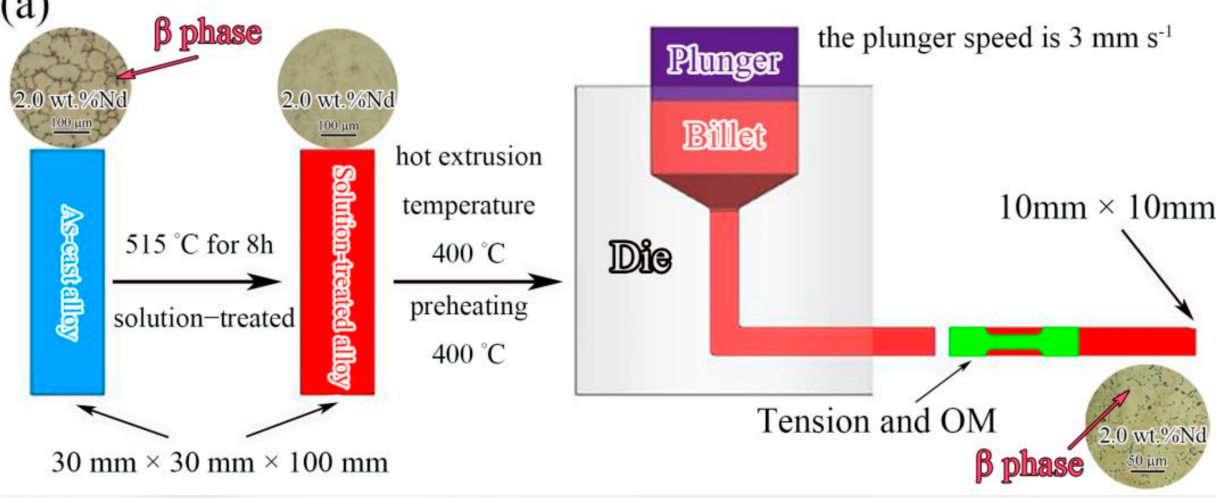

(b)

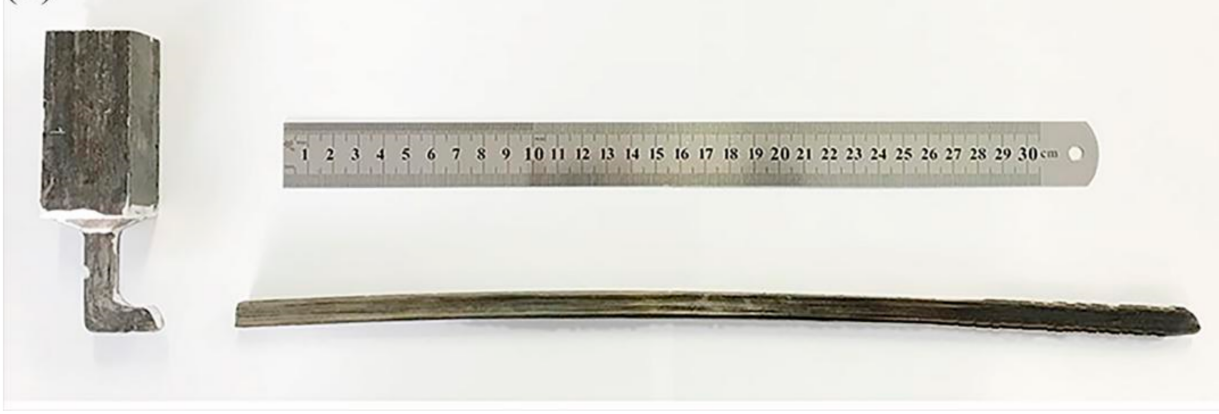

Figure 1. IEECAP process (a) and macrograph of the IEECAPed sample (b).

\section{Results and Discussion}

\subsection{Microstructure}

The initial microstructure of the $\mathrm{Mg}-2.0 \mathrm{Nd}-2.0 \mathrm{Sm}-0.4 \mathrm{Zn}-0.4 \mathrm{Zr}$ alloy before the IEECAP can be observed in Figure 1. The microstructure of the as-cast Mg-2.0Nd-2.0Sm- $0.4 \mathrm{Zn}-0.4 \mathrm{Zr}$ alloy consisted of equiaxed grains and the $\beta$ phase [3]. After solution treatment, $\beta$ phase was dissolved in $\alpha-\mathrm{Mg}$ matrix. The microstructure of IEECAPed and subsequently aged $\mathrm{Mg}-\mathrm{xNd}-2.0 \mathrm{Sm}-0.4 \mathrm{Zn}-0.4 \mathrm{Zr}$ alloys with different content of $\mathrm{Nd}$ element were investigated by OM. As shown in Figure 2, the microstructure of the alloys mainly consisted of equiaxed grains, and the addition of $\mathrm{Nd}$ element could remarkably refine the grain size. In order to quantitatively analyze the grain size, the relation curve of grain size with $\mathrm{Nd}$ addition was given in Figure 3. In the Nd-free alloy, it exhibited coarse grain $(29.7 \mu \mathrm{m})$. When $\mathrm{Nd}$ element increased to $2.5 \mathrm{wt} . \%$, the grain size was the finest $(10.9 \mu \mathrm{m})$. It is worth mentioning that some second phases formed directionally in the alloys when the Nd element exceed $1.0 \mathrm{wt} . \%$. However, directionality of distribution of the second phases was not obvious as the $\mathrm{Nd}$ element exceed $2.0 \mathrm{wt} . \%$. According to the morphology of the second phases and the composition of the alloys, the second phases is $\beta$ phase [22]. In general, the grain refinement is attributed to the solute drag mechanism and second phase pinning mechanism. During the extrusion process, more dislocations can be pinned by the obstacles (solute atoms and second phase particles, etc.), which leads to an increase in the density of dislocations, and the nucleation of recrystallized grain can be further promoted [23]. Moreover, the $\beta$ particles can block grain boundaries and prevent recrystallized grain growth [23]. 


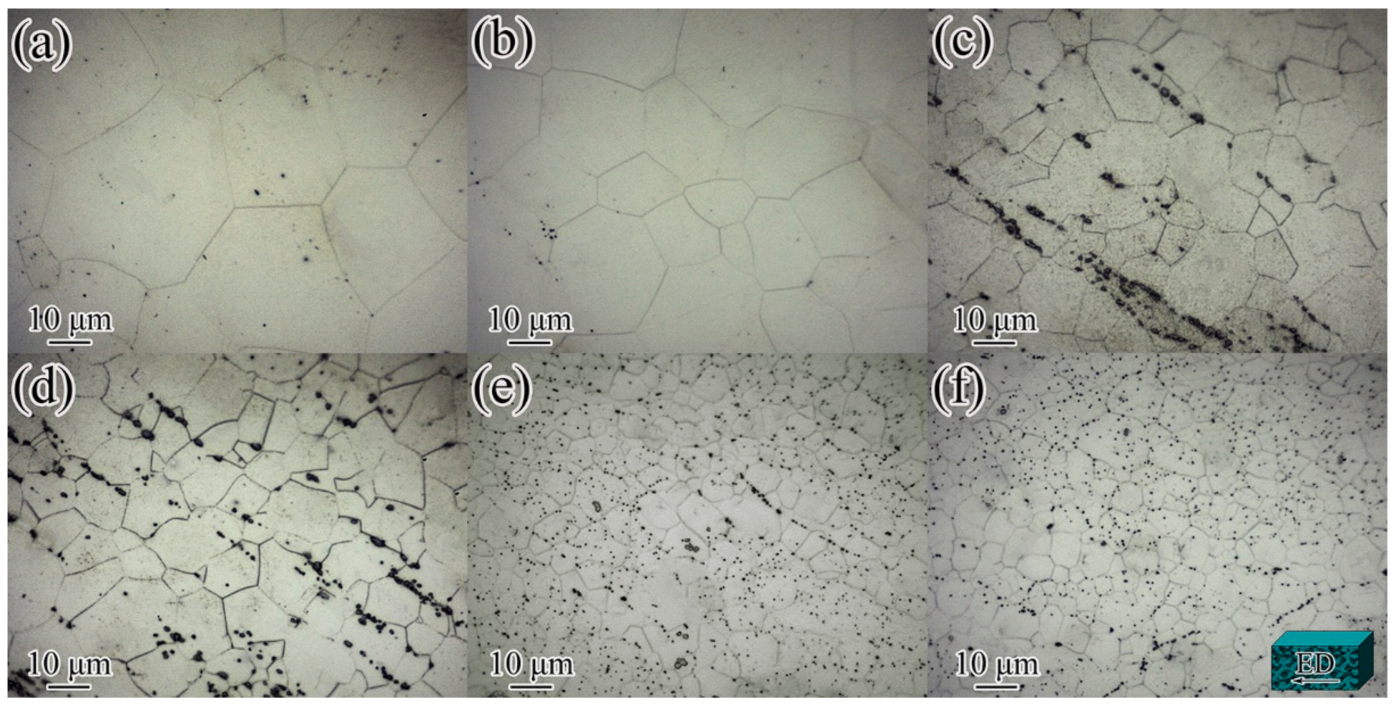

Figure 2. Optical microstructure of the IEECAPed and subsequently aged Mg-xNd-2.0Sm-0.4Zn-0.4Zr alloys with different Nd content (wt.\%): (a) 0, (b) 0.5, (c) 1.0, (d) 1.5, (e) 2.0 and (f) 2.5 .

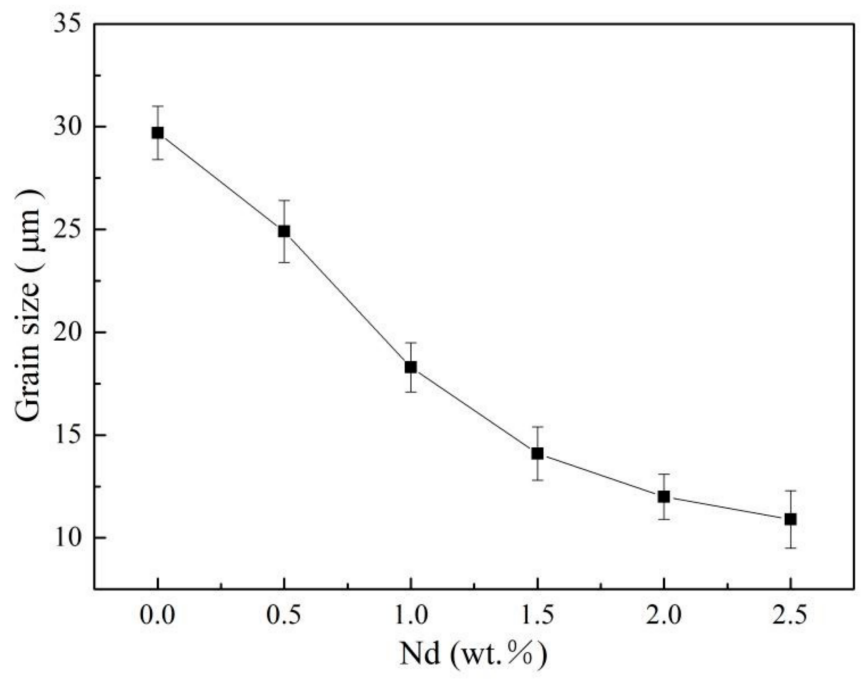

Figure 3. Grain size of the IEECAPed and subsequently aged Mg-xNd-2.0Sm-0.4Zn-0.4Zr alloys by $\mathrm{Nd}$ addition.

The TEM observation and selected area electron diffraction (SAED) patterns was employed to investigate the nano-scaled precipitates in the IEECAPed and subsequently aged Mg-2.0Sm-0.4Zn-0.4Zr alloy. Figure 4a showed the TEM micrographs of the alloys along $[11 \overline{2} 0]_{\alpha}$ zone axis. It can be seen that the nano-scaled lamellar precipitates and granular precipitates occurred in $\alpha-\mathrm{Mg}$ matrix. Moreover, most of the lamellar precipitates formed in the basal plane of $\alpha-\mathrm{Mg}$ matrix, a few lamellar precipitates formed in the prismatic planes. In addition, fewer coarse second phases existed in $\alpha-\mathrm{Mg}$ matrix. To further study the nano-scaled prismatic lamellar precipitates, basal lamellar precipitates, granular precipitates and coarse second phases, the high-resolution transmission electron micrography (HRTEM) and fast Fourier transform (FFT) were employed. The results are shown in Figure $4 b-d$, respectively. The nano-scaled prismatic lamellar precipitates, basal lamellar precipitates and granular precipitates were completely coherent with $\alpha$ $\mathrm{Mg}$ matrix. The granular precipitates were typically less than $5 \mathrm{~nm}$. The length of the lamellar precipitates was approximately $20 \mathrm{~nm}$. According to the morphology, size and the orientation relationship, the basal lamellar precipitates, granular precipitates, prismatic 
lamellar precipitates and coarse second phases are identified as $\gamma^{\prime}$ phase, cluster of atoms, $\beta^{\prime}$ phase and $\beta_{1}$ phase, respectively [20].

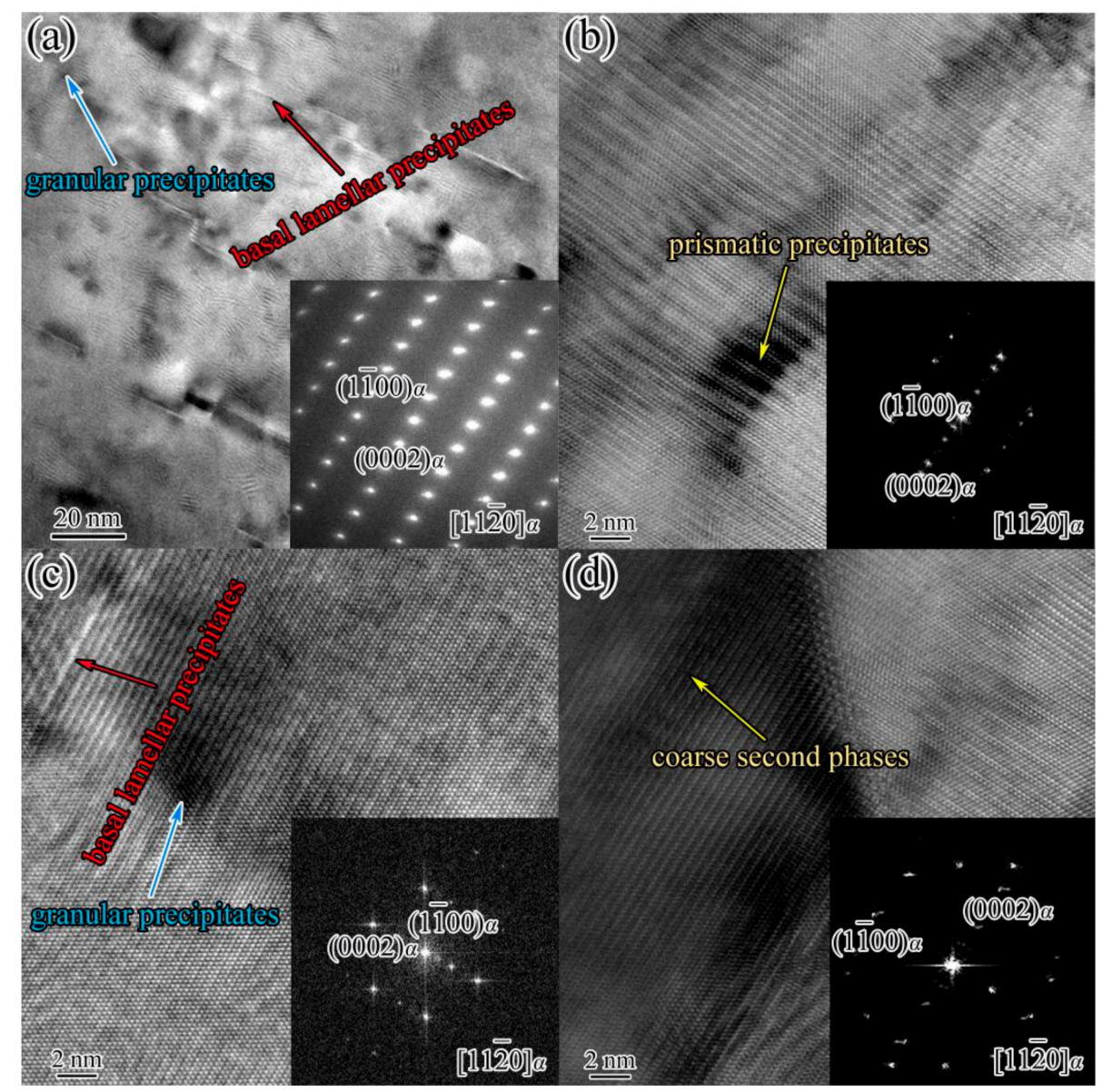

Figure 4. The TEM micrographs and SAED patterns of the IEECAPed and subsequently aged Mg$2.0 \mathrm{Sm}-0.4 \mathrm{Zn}-0.4 \mathrm{Zr}$ alloy along $[1 \overline{2} 0]_{\alpha}$ zone axis. (a) TEM micrograph and SAED patterns of the basal lamellar precipitates and granular precipitates; (b) HRTEM image of the prismatic lamellar precipitates; (c) HRTEM image of the granular precipitates and basal lamellar precipitates; (d) HRTEM image of the coarse second phases.

High magnification TEM micrographs of the IEECAPed and subsequently aged MgxNd-2.0Sm-0.4Zn-0.4Zr alloys ( $x=0.5 \mathrm{wt} . \%, 1.0 \mathrm{wt} . \%, 1.5 \mathrm{wt} . \%$ and $2.0 \mathrm{wt} . \%)$ were employed to study the effect of the $\mathrm{Nd}$ element of precipitates. As shown in Figure $5 \mathrm{a}-\mathrm{d}$, the prismatic lamellar precipitates and the granular precipitates still existed in $\alpha-\mathrm{Mg}$ matrix. Moreover, the size of these precipitates showed no visible changes compared with the Nd-free alloy. For further research of the granular precipitates in the alloys, the HRTEM and FFT image of the granular precipitates in the Mg-2.0Nd-2.0Sm- $0.4 \mathrm{Zn}-0.4 \mathrm{Zr}$ alloy along $[11 \overline{2} 0]_{\alpha}$ zone axis were shown in Figure $5 \mathrm{e}$, which showed that the granular precipitates were still completely coherent with the $\alpha-\mathrm{Mg}$ matrix. The inverse Fourier-filtered transformation (IFFT) was employed to further analyze the effect of the granular precipitates on the atomic arrangement in $\alpha-\mathrm{Mg}$ matrix. Figure $5 \mathrm{f}$ shows the IFFT image and the lattice fringes obtained by IFFT corresponding to the box in Figure 5e. As shown in Figure 5f, the interatomic distance around granular precipitates slightly differ in $\alpha-\mathrm{Mg}$ matrix, which was attributed to the lattice distortions caused by the solute atoms. More importantly, these non-negligible local distortions formed within the granular precipitates, and they were conducive to improve the mechanical properties [24]. 


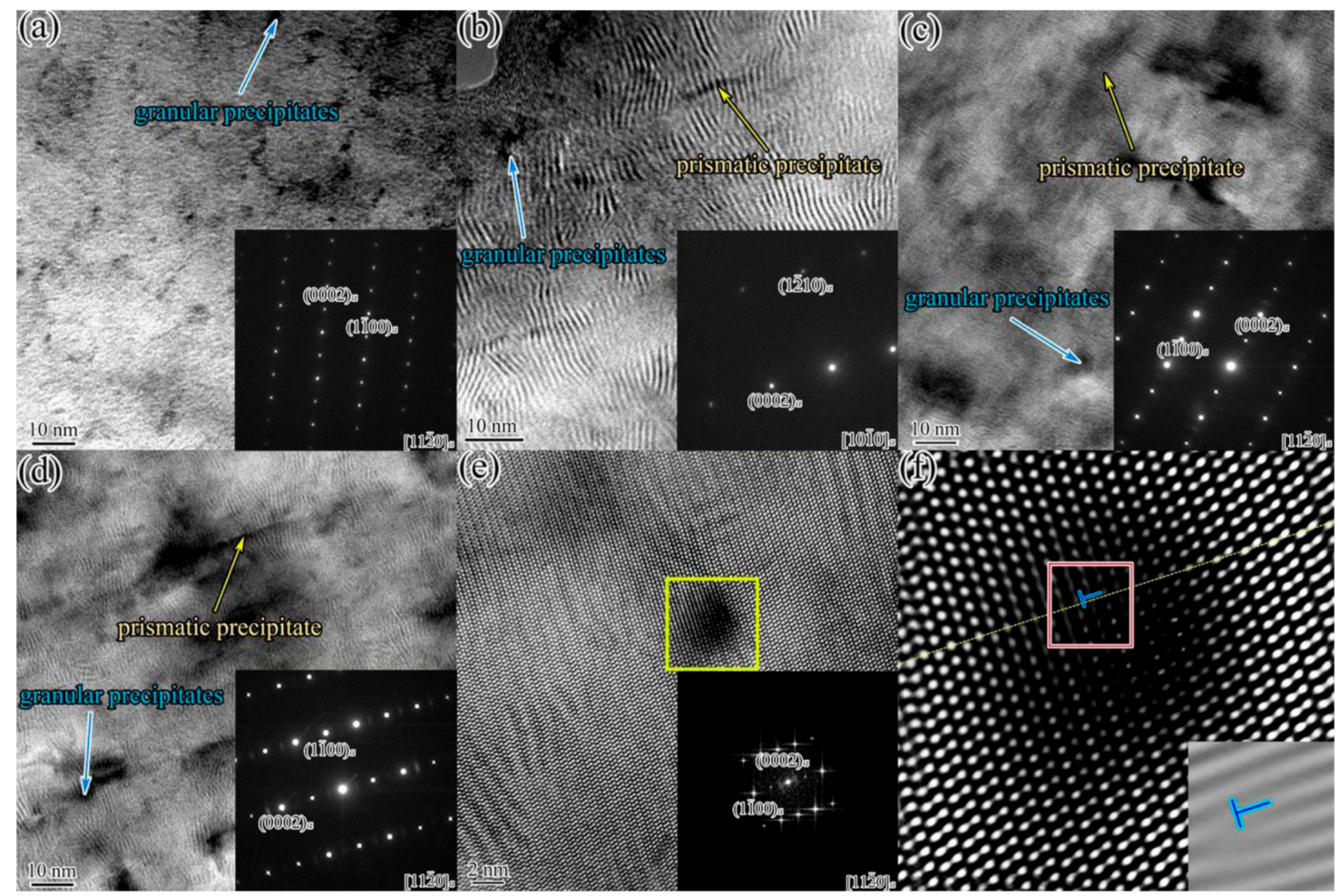

Figure 5. TEM micrographs and SAED patterns of the IEECAPed and subsequently aged Mg-xNd-2.0Sm-0.4Zn-0.4Zr alloys with different $\mathrm{Nd}$ content (wt.\%): (a) 0.5, (b) 1.0, (c) 1.5, (d) 2.0. (e) HRTEM images of the granular precipitates in $\mathrm{Mg}-2.0 \mathrm{Nd}-2.0 \mathrm{Sm}-0.4 \mathrm{Zn}-0.4 \mathrm{Zr}$ along $[11 \overline{2} 0]_{\alpha}$ zone axis; (f) IFFT image and the lattice fringes obtained by IFFT of the selected area from (e).

The TEM micrograph of the IEECAPed and subsequently aged Mg-2.5Nd-2.0Sm$0.4 \mathrm{Zn}-0.4 \mathrm{Zr}$ alloys along $[0001]_{\alpha}$ zone axis and $[11 \overline{2} 0]_{\alpha}$ zone axis are shown in Figure $6 \mathrm{a}, \mathrm{b}$, respectively. Prismatic lamellar precipitates and granular precipitates existed in aged $\mathrm{Mg}-2.5 \mathrm{Nd}-2.0 \mathrm{Sm}-0.4 \mathrm{Zn}-0.4 \mathrm{Zr}$ alloy. The amount of the precipitates significantly increased than the Nd-free alloy. In addition, the morphology of the granular precipitates on [0001] $\alpha$ did not evidently change compare to the $[11 \overline{2} 0]_{\alpha}$. Therefore, the addition of the Nd element could observably promote the formation of the precipitates, especially for the granular precipitates and prismatic lamellar precipitates.

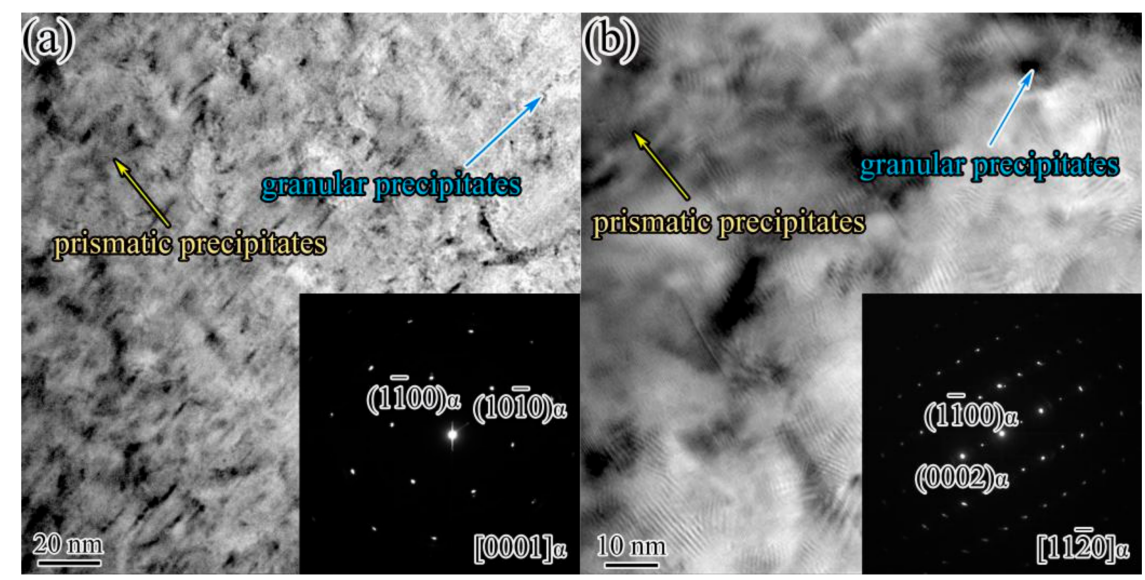

Figure 6. The TEM micrographs and SAED patterns of the IEECAPed and subsequently aged Mg2.5Nd-2.0Sm-0.4Zn-0.4Zr. (a) TEM micrograph and SAED patterns along [0001] $\alpha$ zone axis of the alloy; (b) TEM micrograph and SAED patterns along [11 20$]_{\alpha}$ zone axis of the alloy. 


\subsection{Mechanical Properties and Fracture Analysis}

The change curve of tensile property of the IEECAPed and subsequently aged $\mathrm{Mg}$ $\mathrm{xNd}-2.0 \mathrm{Sm}-0.4 \mathrm{Zn}-0.4 \mathrm{Zr}$ alloys as the function of the content of $\mathrm{Nd}$ element were shown in Figure 7. Upon increasing the $\mathrm{Nd}$ from $0 \mathrm{wt} . \%$ to $2.0 \mathrm{wt} . \%$, tensile strength of the alloys increased from $232 \pm 3 \mathrm{MPa}$ to $315 \pm 5 \mathrm{MPa}$, the yield strength of the alloys increased from $108 \pm 2.5 \mathrm{MPa}$ to $187 \pm 3 \mathrm{MPa}$, and the elongation decreased from $17.5 \pm 0.9 \%$ to $8.5 \pm 0.4 \%$. There are two main reasons for the improvement of the strength of the alloys. First, according to the Hall-Petch formula, grain refinement significantly improved the strength. The grain boundary area was increased by the grain refinement, and the grain boundary acts as a strong barrier to the slip transmission. Second, the precipitates increased obviously in the alloys because of the increase of the $\mathrm{Nd}$ element, which hinders the dislocation movement during the tension process.

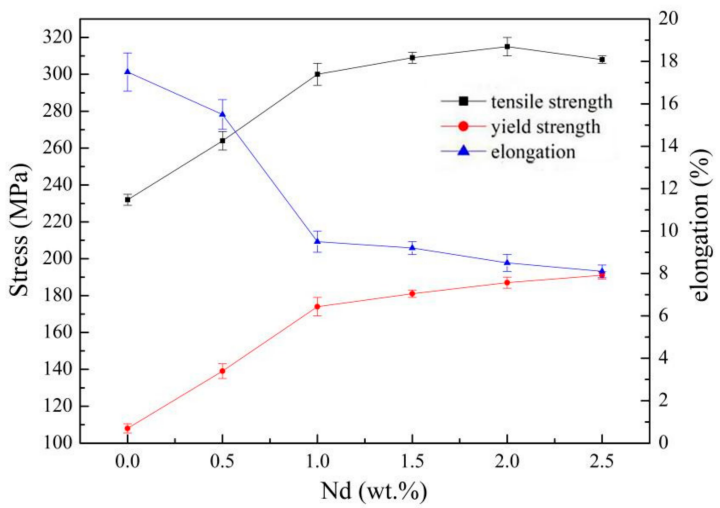

Figure 7. Tensile properties and elongation of the IEECAPed and subsequently aged Mg-xNd-2.0Sm$0.4 \mathrm{Zn}-0.4 \mathrm{Zr}$ alloys.

Figure 8 showed the fracture surfaces of the IEECAPed and subsequently aged $\mathrm{Mg}$ $\mathrm{xNd}-2.0 \mathrm{Sm}-0.4 \mathrm{Zn}-0.4 \mathrm{Zr}$ alloys. It showed that the fractographs of the alloys mainly consisted of tear ridges. In addition to that, some dimples existed in the alloys as the content of $\mathrm{Nd}$ exceed $1.0 \mathrm{wt} . \%$, and the fractographs were progressively refined by addition of the Nd element. The fractographs of the alloys can be classified as transgranular fracture. Figure $8 \mathrm{f}$ showed the fracture surfaces combined with secondary electron (SE) and back scattering electron (BSE) modes for $\mathrm{Mg}-2.5 \mathrm{Nd}-2.0 \mathrm{Sm}-0.4 \mathrm{Zn}-0.4 \mathrm{Zr}$ alloys. The $\beta$ phase is a hard and brittle phase, which act as the source of cracks and induce fracture.

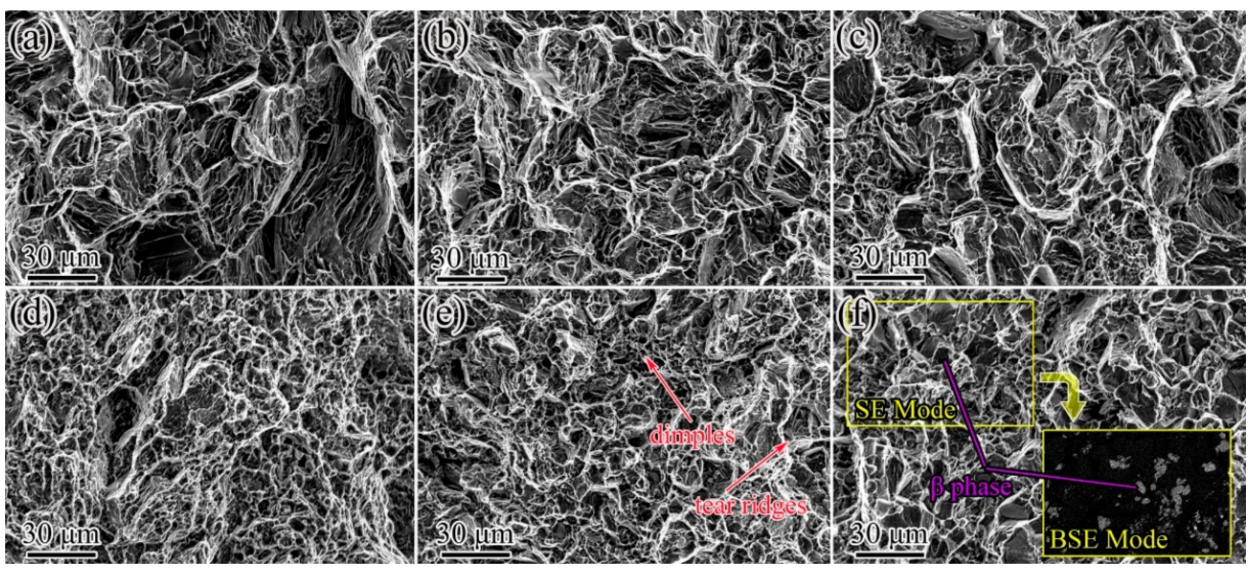

Figure 8. Tensile test of fracture microstructure of the IEECAPed and subsequently aged Mg-xNd2.0Sm-0.4Zn-0.4Zr alloys with different $\mathrm{Nd}$ content (wt.\%): (a) 0, (b) 0.5, (c) 1.0, (d) 1.5, (e) 2.0 and (f) 2.5 . 


\section{Conclusions}

1. The Nd element can remarkably refined the grain size of the IEECAPed and subsequently aged $\mathrm{Mg}-\mathrm{xNd}-2.0 \mathrm{Sm}-0.4 \mathrm{Zn}-0.4 \mathrm{Zr}$ alloys. The grain size of the alloys decreased from $29.7 \mu \mathrm{m}$ to $10.9 \mu \mathrm{m}$ with the content of $\mathrm{Nd}$ element from $0 \mathrm{wt} . \%$ to $2.5 \mathrm{wt} . \%$.

2. The nano-scaled basal lamellar precipitates, prismatic lamellar precipitates, granular precipitates and coarse second phases occurred in IEECAPed and subsequently aged $\mathrm{Mg}-\mathrm{xNd}-2.0 \mathrm{Sm}-0.4 \mathrm{Zn}-0.4 \mathrm{Zr}$ alloys. The amount of the precipitates increased significantly with the addition of the $\mathrm{Nd}$ element, especially with respect to the granular precipitates and prismatic lamellar precipitates.

3. The tensile property of the alloys significantly improved by the addition of $\mathrm{Nd}$. Superior strength and considerable plasticity were observed, as the content of $\mathrm{Nd}$ element reaching to $2.0 \mathrm{wt} . \%$, the tensile strength of the $\mathrm{Mg}-2.0 \mathrm{Nd}-\mathrm{Sm}-\mathrm{Zn}-\mathrm{Zr}$ alloy $(315 \pm 5 \mathrm{MPa}$ ) increased by $35.8 \%$ with respect to the Nd-free alloy ( $232 \pm 3 \mathrm{MPa})$. The fractograph of the alloys were classified as transgranular fracture.

Author Contributions: S.Z., L.W. and Z.W. conceived and designed the experiments; S.Z., K.L. and C.W. performed the experiments; S.Z., K.L., Z.W. and Y.F. analyzed the data; S.Z., D.L. and J.L. acquired the funding and did the project administration; K.L. and S.Z. prepared the original draft; K.L., D.L., S.Z. and J.L. revised the paper and created the final version. All authors have read and agreed to the published version of the manuscript.

Funding: The authors gratefully acknowledge the financial support from the National Natural Science Foundation of China (51804090, 21801070, 51971086), the University Nursing Program for Young Scholars with Creative Talents in Heilongjiang Province (UNPYSCT-2020184), the Natural Science Foundation of Heilongjiang Province (E2018045), and the 'hundred; thousand and ten thousand' Engineering Science and Technology Major Special Project of Heilongjiang Province (2019ZX10A01).

Institutional Review Board Statement: Not applicable.

Informed Consent Statement: Not applicable.

Data Availability Statement: The data presented in this study are available on request from the corresponding author.

Conflicts of Interest: The authors declare no conflict of interest.

\section{References}

1. Guo, E.; Zhao, S.; Wang, L.; Wu, T. Enhanced Age Strengthening of Mg-Nd-Zn-Zr Alloy via Pre-Stretching. Metals 2016, 6, 196. [CrossRef]

2. Pan, H.; Pan, F.; Peng, J.; Gou, J.; Tang, A.; Wu, L.; Dong, H. High-conductivity binary Mg-Zn sheet processed by cold rolling and subsequent aging. J. Alloy. Compd. 2013, 578, 493-500. [CrossRef]

3. Ma, T.; Zhao, S.; Wang, L.; Wang, Z.; Guo, E.; Feng, Y.; Li, J. Influence of Solution Treatment Time on Precipitation Behavior and Mechanical Properties of Mg-2.0Nd-2.0Sm-0.4Zn-0.4Zr Alloy. Materials 2021, 14, 5037. [CrossRef] [PubMed]

4. Zhao, S.C.; Guo, E.J.; Wang, L.; Wu, T.; Feng, Y.C. Effect of pre-compressive strain on microstructure and mechanical properties of Mg-2.7Nd-0.4Zn-0.5Zr alloy. Mater. Sci. Eng. A 2015, 647, 28-33. [CrossRef]

5. Masoudpanah, S.; Mahmudi, R. Effects of rare earth elements and Ca additions on high temperature mechanical properties of AZ31 magnesium alloy processed by ECAP. Mater. Sci. Eng. A 2010, 527, 3685-3689. [CrossRef]

6. Hort, N.; Huang, Y.; Fechner, D.; Störmer, M.; Blawert, C.; Witte, F.; Vogt, C.; Drücker, H.; Willumeit, R.; Kainer, K. Magnesium alloys as implant materials-principles of property design for Mg-RE alloys. Acta Biomater. 2010, 6, 1714-1725. [CrossRef]

7. Chen, D.; Kong, J.; Gui, Z.; Li, W.; Long, Y.; Kang, Z. High-temperature Superplastic Behavior and ECAP Deformation Mechanism of Two-phase Mg-Li alloy. Mater. Lett. 2021, 301, 130358. [CrossRef]

8. Rezaei, A.; Mahmudi, R.; Cayron, C.; Loge, R. Microstructural evolution and superplastic behavior of a fine-grained $\mathrm{Mg}-\mathrm{Gd}-\mathrm{Y}-\mathrm{Ag}$ alloy processed by simple shear extrusion. Mater. Sci. Eng. A 2021, 806, 140803. [CrossRef]

9. Cao, F.; Zhang, J.; Ding, X.; Xue, G.; Liu, S.; Sun, C.; Su, R.; Teng, X. Mechanical properties and microstructural evolution in a superlight Mg-6.4Li-3.6Zn-0.37Al-0.36Y alloy processed by multidirectional forging and rolling. Mater. Sci. Eng. A 2019, 760, 377-393. [CrossRef]

10. Xu, S.; Zheng, M.; Kamado, S.; Wu, K. The microstructural evolution and superplastic behavior at low temperatures of Mg5.00Zn-0.92Y-0.16Zr (wt.\%) alloys after hot extrusion and ECAP process. Mater. Sci. Eng. A 2012, 549, 60-68. [CrossRef] 
11. Biswas, S.; Suwas, S. Evolution of sub-micron grain size and weak texture in magnesium alloy Mg-3Al-0.4Mn by a modified multi-axial forging process. Scr. Mater. 2012, 66, 89-92. [CrossRef]

12. Figueiredo, R.B.; Langdon, T.G. Principles of grain refinement and superplastic flow in magnesium alloys processed by ECAP. Mater. Sci. Eng. A 2009, 501, 105-114. [CrossRef]

13. Guan, K.; Yang, Q.; Bu, F.; Qiu, X.; Sun, W.; Zhang, D.; Zheng, T.; Niu, X.; Liu, X.; Meng, J. Microstructures and mechanical properties of a high-strength Mg-3.5Sm-0.6Zn-0.5Zr alloy. Mater. Sci. Eng. A 2017, 703, 97-107. [CrossRef]

14. Xie, H.; Liu, B.; Bai, J.; Guan, C.; Lou, D.; Pang, X.; Zhao, H.; Li, S.; Ren, Y.; Pan, H.; et al. Re-recognition of the aging precipitation behavior in the Mg-Sm binary alloy. J. Alloy. Compd. 2020, 814, 152320. [CrossRef]

15. Xia, X.; Luo, A.A.; Stone, D.S. Precipitation sequence and kinetics in a Mg-4Sm-1Zn-0.4Zr (wt\%) alloy. J. Alloy. Compd. 2015, 649, 649-655. [CrossRef]

16. Su, X.; Li, D.J.; Xie, Y.C.; Zeng, X.Q.; Ding, W.J. Effect of Sm on the Microstructure and Mechanical Property of Mg-xSm-0.4Zn-0.3Zr Alloys. Mater. Sci. Forum. 2013, 747, 238-244. [CrossRef]

17. Xu, X.; Xu, C.; Wu, D.; Yi, G.; Feng, P. Effect of Nd on microstructure and mechanical properties of as-extruded Mg-Y-Zr-Nd alloy. J. Mater. Sci. Technol. 2017, 33, 926-934. [CrossRef]

18. Wang, B.; Guan, S.; Wang, J.; Wang, L.; Zhu, S. Effects of Nd on microstructures and properties of extruded Mg-2Zn-0.46Y-xNd alloys for stent application. Mater. Sci. Eng. B 2011, 176, 1673-1678. [CrossRef]

19. Cano-Castillo, G.; Victoria-Hernández, J.; Bohlen, J.; Letzig, D.; Kainer, K.U. Effect of Ca and Nd on the microstructural development during dynamic and static recrystallization of indirectly extruded Mg-Zn based alloys. Mater. Sci. Eng. A 2020, 793, 139527. [CrossRef]

20. Sanaty-Zadeh, A.; Luo, A.; Stone, D. Comprehensive study of phase transformation in age-hardening of $\mathrm{Mg}-3 \mathrm{Nd}-0.2 \mathrm{Zn}$ by means of scanning transmission electron microscopy. Acta Mater. 2015, 94, 294-306. [CrossRef]

21. Zhao, S.; Guo, E.; Cao, G.; Wang, L.; Lun, Y.; Feng, Y. Microstructure and mechanical properties of Mg-Nd-Zn-Zr alloy processed by integrated extrusion and equal channel angular pressing. J. Alloy. Compd. 2017, 705, 118-125. [CrossRef]

22. Pike, T.; Noble, B. The formation and structure of precipitates in a dilute magnesium-neodymium alloy. J. Less Common Met. 1973, 30, 63-74. [CrossRef]

23. Jung, I.-H.; Sanjari, M.; Kim, J.; Yue, S. Role of RE in the deformation and recrystallization of Mg alloy and a new alloy design concept for Mg-RE alloys. Scr. Mater. 2015, 102, 1-6. [CrossRef]

24. Wang, W.Y.; Tang, B.; Shang, S.-L.; Wang, J.; Li, S.; Wang, Y.; Zhu, J.; Wei, S.; Wang, J.; Darling, K.A.; et al. Local lattice distortion mediated formation of stacking faults in Mg alloys. Acta Mater. 2019, 170, 231-239. [CrossRef] 